\title{
Diversidad latina y comunicación panhispana en la prensa en español de Nueva York al inicio del siglo XXI
}

Josep Lluís Gómez Mompart

Catedrático de Periodismo. Universitat de València

Resumen:

Las transformaciones de la prensa hispana en Nueva York en la década del cambio de siglo apuntan la configuración de una incipiente identidad cultural panhispánica. Esa identidad panhispánica se muestra gracias al contenido informativo y publicitario de diversos periódicos en español de esa ciudad, pero sobre todo mediante los tres diarios El Diario-La Prensa, Hoy y Noticias del Mundo. La metodología empleada ha sido un análisis cuantitativo-cualitativo de sus contenidos informativos y publicitarios, con el objetivo de evaluar el carácter de esa prensa, además de un somero estudio de campo sobre el comportamiento urbano culturalcomunicativo de los hispanos en esa ciudad.

Palabras clave:

Prensa hispana en EE.UU.; Comunicación panhispánica; Diarios de Nueva York; Comunicación e identidad hispanas.

Abstract:

The changes that have taken place in the Hispanic press in New York in the decade at the turn of the century point out the formation of a new Panhispanic cultural identity. That Panhispanic identity is shown by means of the information and publicity contents of several Spanish newspapers in that city, but especially by means of the three newspapers El Diario-La Prensa, 
Hoy and Noticias del Mundo. The methodology used has been a quantitative-qualitative analysis of the information and publicity contents with the aim to assess the characteristics of that kind of press, apart from some field-work about the urban cultural-communicative behaviour of the Hispanics in that city.

Key words:

Hispanic press in the US; Panhispanic communication; New York newspapers; Hispanic communication and identity.

\section{Introducción}

En los últimos años se produjo un auge en el desarrollo de los medios de comunicación en lengua española en Estados Unidos; una expansión no solamente mediática sino también de todo el ámbito cultural en general de carácter hispánico en ese país. Las razones de este boom son relativamente comprensibles a tenor de la misma evolución de la población de origen latino, 35,3 millones según el último censo de 2000, y con una proyección oficial estimada en unos 47 millones para el censo del 2010. Ese número de hispanos representa, por un lado, haber superado a la minoría negra (la primera hasta entonces) y, por otro, esa cifra equivale en términos cuantitativos a la quinta comunidad hispanohablante del mundo tras México, Colombia, España y Argentina (a la que probablemente ahora ya supera, dado que se considera que varios millones de los inmigrados no censados en EE.UU. son latinoamericanos; si se incluyeran además los habitantes de la isla de Puerto Rico, en conjunto superarían también a los más de 42 millones de habitantes de España). Asimismo, ese número de hispanos supone un potencial económico de compra estimado en unos quinientos mil millones de dólares.

El hecho de que el idioma español ocupe el primer lugar, tras el inglés, entre los ciudadanos de los Estados Unidos ayuda a comprender el campo mediático de carácter hispano en este país, donde -por ejemplo- hay cerca de un millar de medios de comunicación (prensa, radio y televisión), de los cuales más de 500 son publicaciones, y los 500 restantes son emisoras de radio y televisión. Además, el dinero invertido en publicidad en esos medios de comunica- 
ción hispanos alcanzó en el momento de inflexión, hacia finales del siglo pasado, los 1.400 millones de dólares y desde entonces siguió creciendo. Sorprendentemente, no hay muchos estudios sobre ese fenómeno sociocultural y todavía menos los referidos a la prensa y el periodismo hispano en los Estados Unidos.

De aquí que nuestra investigación se sumerja, precisamente, en ese territorio escasamente explorado -a excepción de la TV- como es el auge de los medios de comunicación hispanos en los Estados Unidos, por su creciente importancia en diversos campos y por su relevancia tanto en el contexto internacional como hispanoamericano. Acercarse al hecho en cuestión posibilita entender la dimensión sociocomunicativa y lingüístico-cultural de esa singular manifestación mediática que, juntamente con el resto de la producción cultural hispana, está contribuyendo a la formación de un imaginario simbólico complejo, hasta tal punto que algún autor ya ha hablado de "nación hispana" (Fox, 1997). Pues se trata de una identidad que, de alguna manera, refleja la rica y plural tradición de los Estados Unidos, pero a la vez constituye un epifenómeno de interés para otros estados o países multiculturales, especialmente en el actual proceso de globalización económica y mundialización cultural de la denominada Sociedad de la Información.

Este artículo, sin embargo, parte de una investigación -realizada en buena parte en el 2002 y continuada posteriormente- mucho más amplia de la aquí presentada. Por un lado, inicialmente efectuamos un estado de la cuestión en cuanto a los medios hispanos en Estados Unidos y, por otro, apuntamos el marco contextual de dicho asunto desde la perspectiva de historia de la comunicación social, ya que la significación del mismo y su repercusión, en particular en Estados Unidos, va mucho más allá del ámbito mediático como se revela en el sesgado trabajo de Samuel P. Huntington (2004a) que tantas críticas ha recibido especialmente de mexicanos (Fuentes, 2004; Krauze, 2004). Para ello, había que escoger un momento y un lugar que concentraran los elementos fundamentales del tema, donde además de conocer la evolución de los medios, los sujetos sociales y las circunstancias culturales del fenómeno, pudiéramos averiguar de primera mano y sobre el terreno el alcance del mismo. De acuerdo con ese criterio y también bajo el prisma de los estudios comunicación y ciudad nos decidimos por Nueva York (para cuyo estudio realizamos dos estancias: mayo-junio de 2000 y abril-mayo de 
2003). No sólo es la ciudad con mayor población de los Estados Unidos (8 millones), así como la más rica y plural en actitudes y nacionalidades (también hispanas: una veintena identificadas en el censo de 2000), sino que además es la que cuenta con el mayor número de hispanos de todas las ciudades norteamericanas (2.160.554, un $27 \%$ sobre el total de los habitantes neoyorquinos según el mismo censo).

\section{Hispanos, latinos...}

¿Quiénes forman esta creciente comunidad hispana o panhispana en los Estados Unidos de la que venimos hablando? Los mismos responsables del censo en ese país llevan años intentando buscar un término adecuado que pueda incluir a todos los individuos que comparten raíces hispanas distintivas. Sin duda, no la han resuelto, simplemente lo han simplificado por razones operativas, dado que el nominalismo a ese respecto es exhaustivo y complejo, como bien ha puesto de manifiesto, entre otros, Néstor García Canclini (2003: 6-16), y más aún desde que los migrantes de América Latina, como tantos otros ciudadanos del mundo, también se globalizan. En el censo norteamericano de 1950 se decidió que la forma de agrupar a aquellos ciudadanos era como "personas con español como lengua materna”, en 1960 eran hispanos si tenían un "apellido español”, en 1990 se preguntaba a las personas si se identificaban con una de las doce nacionalidades de origen más habituales entre los inmigrantes y si la respuesta era afirmativa se les marcaba como "hispanas"; el término "hispano" fue sancionado para su uso gubernamental en 1968 (Melville, 1994: 90). En el censo de 2000 se utilizaron alternativamente los términos "Spanish / Hispanic / Latino" para a continuación preguntar por tres nacionalidades concretas: mexicana (a la que se le daba también las alternativas de mexicanaamericana y chicana), puertorriqueña o cubana, y si no, había que especificar la nacionalidad de procedencia.

Durante bastante tiempo, ha habido también un debate respecto a la utilización del término "latino" o "hispano". Según Davis (2000:12), en California y Texas se prefiere el primero, mientras que en el sur de Florida su utilización se consideraría de mal gusto; sin embargo, en el este se usan ambos términos indistintamente; asimismo, este autor opina que ambos términos tienen su origen en imposiciones ideológicas europeas del siglo XIX: "hispanicidad" de la 
España liberal y "latinidad” de la Francia de Napoleón III. Por su parte, Melville (1994: 92) opina que la forma "latino" es la de mayor aceptación entre la misma comunidad hispana. Nosotros hemos optado por la palabra "hispano" en la mayoría de los casos ya que pensamos que representa mejor algunos de los aspectos en los que nos centramos en esta investigación, como es sobre todo el de la lengua. Y también porque nos parece legítimo -como bien señala García Canclini (2003: 8) - "identificar los nombres fundamentales de las identidades y declarar, desde el relativismo filosófico y antropológico, que todos son válidos".

En muchas ocasiones también se ha identificado latino o hispano con "católico", pero esta relación es cada vez más difícil de mantener. A pesar de que los hispanos todavía nutren de fieles muchas de las iglesias católicas de Estados Unidos ${ }^{1}$, cada vez son más los que abrazan otras confesiones cristianas, sobre todos evangélicas, bien desde su país de origen o bien a su llegada a Estados Unidos porque es en estas comunidades religiosas donde encuentran más ayuda práctica, lo que les lleva a convertirse posteriormente. Un fenómeno parecido está produciéndose con la religión musulmana; se calcula que entre 25.000 y 40.000 hispanos de Estados Unidos se han convertido al Islam en los últimos años, unos por insatisfacción con la Iglesia católica ${ }^{2}$, otros, por encontrar en las comunidades islámicas la protección y la ayuda que sus compatriotas o las comunidades cristianas no les ofrecen (El País, 12/06/2002).

A pesar de la voluntad de encontrar un nombre común para todas las personas procedentes de los distintos países de Norte América, Centro América, el Caribe y Sudamérica, no hay que olvidar la diversidad de nacionalidades y culturas que hay detrás de esta comunidad que estamos llamando "hispana"; de aquí que convenga hablar de "panhispana". Se calcula que 20,6 millones de hispanos tienen raíces mexicanas; 3,4 millones son puertorriqueños; 1,8 millones son cubanos; 1,7 millones proceden de los distintos países de Centroamérica y El Caribe, y

1 Esta Prueba de ello podría ser la monumental catedral construida por Rafael Moneo e inaugurada el 3 de septiembre de 2002, en Los Ángeles, una ciudad con 1.719.073 hispanos, es decir un 46,5\% del total de la población, según el censo de 2000 .

2 Algo parecido, aunque por razones terriblemente dramáticas, ha ocurrido en los últimos años en Ruanda, un país predominantemente católico, donde diez años después de las crueles matanzas, el número de musulmanes aumentó por el descrédito que la Iglesia Católica adquirió tras el comportamiento de algunos sacerdotes y monjas de este credo durante aquel genocidio (Lacey, 2004). 
1,4 millones de países de América del Sur, con predominio de Colombia (El País, 09/09/2001). Y si nos centramos en las tres ciudades más "latinas" de Estados Unidos, comprobamos que, a pesar del predominio de un grupo determinado -sobre todo de los mexicanos en Los Ángeles-, la cierta multiculturalidad hispana que ya se apuntaba en la última década del siglo XX -como se muestra en la Tabla I con datos del censo de 1990- ha ido ampliándose en general y particularmente en Nueva York como veremos más adelante con detalle.

Tabla I. Las tres grandes ciudades "latinas" de EE.UU.

\begin{tabular}{|l|c|c|c|c|c|}
\hline $\begin{array}{l}\text { Los } \\
\text { Ángeles }\end{array}$ & Mexicanos 80\% & $\begin{array}{c}\text { Salvadore- } \\
\text { ños 6\% }\end{array}$ & $\begin{array}{c}\text { Guatemalte- } \\
\cos 3 \%\end{array}$ & & \\
\hline Miami & Cubanos 66\% & $\begin{array}{c}\text { Nicaragüen } \\
\text { ses } 11 \%\end{array}$ & $\begin{array}{c}\text { Puertorrique- } \\
\text { nos 6\% }\end{array}$ & & \\
\hline $\begin{array}{l}\text { Nueva } \\
\text { York }\end{array}$ & $\begin{array}{c}\text { Puertorrique- } \\
\text { ños } 46 \%\end{array}$ & $\begin{array}{c}\text { Dominica- } \\
\text { nos } 15 \%\end{array}$ & $\begin{array}{c}\text { Colombia- } \\
\text { nos 5\% }\end{array}$ & $\begin{array}{c}\text { Mexica- } \\
\text { nos 4\% }\end{array}$ & $\begin{array}{c}\text { Ecuatoria- } \\
\text { nos } 4 \%\end{array}$ \\
\hline
\end{tabular}

Fuente: Davis, 2000: 16.

Esta diversidad de las comunidades hispanas se ve reforzada por los lazos que cada una de ellas mantiene con su país de origen. Se ha hablado (Davis, 2000: 77) de que los edificios de algunas barriadas urbanas no son sólo individuos o casas, sino comunidades enteras transnacionalizadas. Uno de los procesos de inmigración más habituales es que, a la marcha de unos cuantos habitantes de una población hacia -en este caso- un lugar de los Estados Unidos les sigan otros llamados y acogidos por los primeros, de manera que se crean auténticas bolsas de trabajo y también de población, evidenciándose la multiplicidad e importancia de los flujos. Gracias a los medios de comunicación (teléfonos móviles, internet, radio y televisión vía satélite, mensajería urgente) y de transporte actuales (vuelos económicos, envíos fáciles de dinero y paquetes) estos inmigrantes pueden mantenerse en contacto fácilmente con sus países de origen, sin "cortar" culturalmente como antaño: es decir, pudiendo ser locales y globales a la vez, o sea, "glocales". Y, en muchas ocasiones, también pueden influir con su dinero en nuevas formas de vida adoptadas por aquellos que se quedaron en casa o incluso en las decisiones políticas. 
Con frecuencia, los grupos de emigrados en Estados Unidos han jugado un papel importante en la vida política de sus países de origen, bien a través de la consecución de fondos, bien con la formación de grupos de presión. De hecho, el anterior presidente de la República Dominicana, Leonel Fernández, era un inmigrante que había crecido en Nueva York y que siempre ha conservado su tarjeta de residente de Estados Unidos, adonde pensaba volver una vez finalizado su mandato. Así, por ejemplo, los parlamentos dominicano y mexicano han valorando la posibilidad de permitir que los inmigrantes puedan votar ${ }^{3}$ en Estados Unidos.

Otra forma de mantener la relación con sus países es a través de actividades colectivas, por ejemplo, actos sociales o competiciones deportivas. En el análisis de los periódicos neoyorquinos, pudimos comprobar cómo se celebra la elección de "Miss ...." dentro de una determinada comunidad hispana, así como la rivalidad entre distintos equipos locales de fútbol o béisbol procedentes del mismo país, que posteriormente pueden competir con equipos de otros países también.

\subsection{Hispanos en Nueva York}

La evolución de los hispanos en el Estado de Nueva York en los últimos sesenta años fue la que se muestra en la Tabla II. Según el último censo de 2000 (los censos en EE.UU. son cada diez años), la población hispana de ese estado se repartió por nacionalidades de origen de la manera en que aparece en la Tabla III. Los hispanos en Estados Unidos, a diferencia de la mayoritaria preferencia de otros grupos a vivir en zonas suburbanas, tienden desde hace bastantes años a vivir en las ciudades. Algunos consideran que sin esta población latina, muchas grandes ciudades estadounidenses estarían disminuyendo peligrosamente de tamaño ante la huída de blancos no latinos y negros hacia otras zonas. De hecho, la gran mayoría de las comunidades hispanas están concentradas en las grandes ciudades, como se puede comprobar en la Tabla IV. Tal como se ve en dicha tabla, Nueva York es la ciudad estadounidense con mayor número de población hispana, asentada hasta hace unos años sobre todo en tres

\footnotetext{
3 Los ejemplares de los tres diarios analizados de Nueva York (2000) coincidieron con elecciones tanto en República Dominicana como en Perú, por lo que pudimos comprobar el enorme interés que las elecciones hispanoamericanas despertaban en las comunidades procedentes de estos países que viven en esa ciudad.
} 
de las cinco zonas en que está dividida la ciudad: Manhattan, el Bronx y Queens, tal como puede apreciarse en la Tabla V, pero donde ya se evidencia como también han crecido los hispanos en Brooklyn e incluso en Staten Island.

Tabla II. Evolución de los hispanos en el estado de Nueva York

\begin{tabular}{|c|c|c|}
\hline Año & No de hispanos & \% sobre total población \\
\hline 2000 & 2.867 .583 & 12,5 \\
\hline 1990 & 2.214 .026 & 12,3 \\
\hline 1980 & 1.659 .300 & 9,5 \\
\hline 1970 & 1.455 .941 & 8 \\
\hline 1940 & 129.071 & 1 \\
\hline
\end{tabular}

Fuente: Gibson y Jung, 2002: 65.

Tabla III. Reparto de hispanos en el Estado de Nueva York

\begin{tabular}{|c|c|c|}
\hline Puertorriqueños & 1.050 .293 & $36,6 \%$ \\
\hline Dominicanos & 455.061 & $15,9 \%$ \\
\hline Mexicanos & 260.889 & $9,15 \%$ \\
\hline Ecuatorianos & 123.472 & $4,3 \%$ \\
\hline Colombianos & 104.179 & $3,6 \%$ \\
\hline Salvadoreños & 72.713 & $2,5 \%$ \\
\hline Cubanos & 62.590 & $2,2 \%$ \\
\hline Peruanos & 37.340 & $1,3 \%$ \\
\hline Hondureños & 35.135 & $1,2 \%$ \\
\hline Guatemaltecos & 29.074 & $1,0 \%$ \\
\hline Panameños & 20.055 & $0,7 \%$ \\
\hline Argentinos & 14.407 & $0,5 \%$ \\
\hline Españoles & 13.017 & $0,5 \%$ \\
\hline
\end{tabular}




\begin{tabular}{|c|c|c|}
\hline Chilenos & 9.937 & $0,3 \%$ \\
\hline Venezolanos & 8.826 & $0,3 \%$ \\
\hline Nicaragüenses & 8.033 & $0,3 \%$ \\
\hline Costarricenses & 7.845 & $0,3 \%$ \\
\hline Bolivianos & 4.221 & $0,1 \%$ \\
\hline Uruguayos & 3.366 & $0,1 \%$ \\
\hline Paraguayos & 2.668 & $0,1 \%$ \\
\hline Otros sudamericanos & 9.971 & $0,3 \%$ \\
\hline Otros centroamericanos & 9.020 & $0,3 \%$ \\
\hline Otros hispanos o latinos & 525.471 & $18,3 \%$ \\
\hline Total & 2.867 .583 & $100 \%$ \\
\hline
\end{tabular}

Fuente: Elaboración propia con datos del último censo (2000)

Tabla IV. Las diez ciudades de EE.UU. con mayor población hispana (2000)

\begin{tabular}{|ccc|}
\hline Ciudades & No de hispanos & \% sobre total población \\
\hline Nueva York (NY) & 2.160 .554 & 27 \\
\hline Los Ángeles (CA) & 1.719 .073 & 46,5 \\
\hline Chicago (IL) & 753.644 & 26 \\
\hline Houston (TX) & 730.865 & 37,4 \\
\hline San Antonio (TX) & 671.394 & 58,7 \\
\hline Phoenix (AZ) & 449.972 & 34,1 \\
\hline El Paso (TX) & 431.875 & 76,6 \\
\hline Dallas (TX) & 422.587 & 35,6 \\
\hline San Diego (CA) & 310.752 & 25,4 \\
\hline Miami (FL) & 238.351 & 65,8 \\
\hline
\end{tabular}

Fuente: Elaboración propia con datos del último censo (2000). 
Tabla V. Hispanos de la ciudad de Nueva York por sus cinco áreas (2000)

\begin{tabular}{|c|c|c|}
\hline Área & No de hispanos & \% sobre total población \\
\hline Bronx & 644.705 & 48,4 \\
\hline Queens & 556.605 & 25 \\
\hline Brooklyn & 487.878 & 19,8 \\
\hline Manhattan & 417.816 & 27,2 \\
\hline Staten Island & 53.550 & 12,1 \\
\hline
\end{tabular}

Fuente: Elaboración propia con datos del último censo (2000).

Pero, a su vez, Nueva York es también la ciudad de mayor variedad cultural y étnica. A diferencia de Los Ángeles, donde hay una gran concentración de inmigrantes mexicanos (80\% del total de la comunidad hispana), Nueva York acoge a hispanos procedentes de todos los países hispanoamericanos (como hemos especificado y cuantificado más arriba). Además, todas las barriadas de Nueva York consideradas latinas, tienen también otras grandes minorías, por ejemplo, afroamericanas, asiáticas, negrocaribeñas, europeas nuevas, etc., las cuales representan entre el 30 y el 45\% de la población de esos lugares (Davis, 2000: 41).

En 1996, el Institute for Puerto Rican Policy publicó un atlas de la población hispana en Nueva York donde identificaba, al menos, 21 barriadas latinas en cuatro de las cinco zonas (Bronx, Manhattan, Queens, Brooklyn y Staten Island) en las que se divide la ciudad, entre ellas, 11 eran predominantemente puertorriqueñas en el sur del Bronx; 2 de mayoría dominicana en upper Manhattan (Washington Heights y Morningside Heights); otras 2 eran enclaves de mezcla de sudamericanos en Queens; y el resto era más difícil de clasificar.

Nuestra observación sobre el terreno (mayo-junio de 2000 y abril-mayo de 2003), corroborada con conocedores del tema, nos permitió comprobar la ampliación de las zonas hispanas en los cinco grandes barrios neoyorquinos, respecto a la década anterior, observándose al mismo tiempo una mayor densidad en cada una de ellas, así como en otras nuevas, además de una clara pluralidad hispana en la mayoría de las mismas. 


\section{Prensa hispana neoyorquina}

Tras la guerra hispano-americana de 1898 por la que España cedía Puerto Rico a Estados Unidos y éste, a su vez, asumía también el gobierno de Cuba, aunque sin anexionarse la isla, la presencia y las actuaciones de los activistas de origen cubano y puertorriqueño en Nueva York disminuyó enormemente. Sin embargo, al inicio del nuevo siglo se pudo hablar ya de una comunidad hispana en Nueva York -cuyos inicios cabe datarlos hacia 1830 (Torres Santiago, 1997)-, formada por puertorriqueños, cubanos y españoles, población que fue creciendo a medida que se adentraba en el siglo XX y hasta los años de la Depresión en la década de 1930. El periodismo -dominado por los puertorriqueños en aquel momento- se convirtió en el portavoz de la situación socioeconómica de los hispanos, de sus sentimientos y sus aspiraciones. De hecho, el político puertorriqueño Luis Muñoz Rivera, que emigró desde la isla hasta Nueva York, fundó en 1901 un semanario bilingüe, Puerto Rico Herald, posiblemente el primero de estas características en Nueva York.

Sin embargo, el periódico que parece ser que se convirtió en el auténtico portavoz de la comunidad hispana de Nueva York a principios del siglo XX fue el semanario La Prensa, publicado por primera vez el 12 de octubre -fecha muy significativa en uno u otro sentido para la comunidad hispana- de 1913. Fundado por Rafael Viera, fue a partir del 4 de junio de 1918, bajo la dirección de V.H. Collao, cuando se convirtió en diario y posteriormente fue adquirido por la familia Camprubí, que en 1958 lo vendió a Fortunato Pope.

Durante varias décadas habían aparecido diversas publicaciones hispanas en la ciudad (Sangre Latina, Revista Pan-Americana, La Paz y el Trabajo - Revista Mensual de Comercio, Literatura, Ciencias, Artes, La Hacienda o Gráfico): algunas semanales o quincenales, muchas de ellas especializadas, otras de carácter amateur. Pero todas ellas se caracterizaron por sus esfuerzos por cohesionar la comunidad hispana, una tarea ardua en Nueva York debido a la cada vez más diversa procedencia de los hispanos asentados en esta ciudad. También querían proteger la pureza de la cultura hispana contra los peligros de la asimilación y su intención era crear un “Trópico en Manhattan” (Kanellos, 1994: 248). De la década de los 30 a la de los 50 la inmigración desde Puerto Rico llegó a alcanzar proporciones de diáspora, a medida que 
la situación económica empeoraba en la isla y que Estados Unidos tenía necesidad de mano de obra durante la II Guerra Mundial. Por otra parte, en la década de los treinta hubo una nueva ola de inmigración desde España a causa de la Guerra Civil. En esta época, Nueva York vio la creación de nuevos periódicos -algunos de marcado carácter sindicalista y socialista (Vida Obrera [1930], Alma Boricua [1934], España libre [1943], y Cultura Proletaria [1943])con la intención de servir a estos inmigrantes.

En 1948, el dominicano Porfirio Domenicci había fundado El Diario, que a partir de 1961 y en manos del empresario de la comunicación O.Roy Chalk pasó a denominarse El Diario de Nueva York. Chalk era el propietario de la compañía Diversified Media y, cuando en 1963 compró también La Prensa, decidió fusionarlos en lo que es hasta el día de hoy El Diario - La Prensa, el más importante y tradicional hasta el nuevo período finisecular cuando emergió con fuerza un competidor directo, el diario Hoy, hecho con medios y sin ningún lastre ni compromiso histórico. El periódico hispano-neoyorquino decano ha pasado por distintas manos: en 1981 fue vendido a Ganett Company, una importante corporación de medios de comunicación, y en 1989 a El Diario Associates, Inc.; posteriormente fue la propietaria la Latin Communications Group, compañía que en el 2003 fue absorbida por el consorcio canadiense CPK Media.

Por otra parte, desde primeros de 2004, El Diario - La Prensa creó, juntamente con el diario hispano de Los Ángeles La Opinión, la compañía Impremedia con el fin de potenciar sus empresas y publicaciones en español. Paralelamente se estudiaba la pretensión de crear una red nacional de diarios hispanos de gran difusión y que, en principio, iba a estar compuesta por cuatro destacados periódicos: La Opinión (de Los Ángeles con 125.000 ejemplares), El Nuevo Herald (de Miami con 90.000), El Diario - La Prensa (de N.Y. con 60.000) y el semanario La Raza (de Chicago con 190.000).

Durante las décadas siguientes a los años sesenta del siglo XX, y con el crecimiento continuado -en cantidad y variedad- de la población hispana de Nueva York, hubo renovados intentos de crear una prensa en lengua española dirigida a la comunidad hispana. La mayoría apenas sobrevivieron unos años. No fue hasta 1980 cuando el 22 de abril de ese año se fundó otro de los diarios hispanos, Noticias del Mundo, que hasta finales de abril de 2004 si- 
guió publicándose en la ciudad ${ }^{4}$, a cargo de News World Communications, Inc., una organización fundada en 1976 por el Reverendo Sun Myung Moon y su Iglesia Internacional de la Unificación, que posee también otros periódicos como el Washington Times o el New York City Tribune, además la agencia de noticias United Press Internacional (UPI).

El último diario hispano en hacer su aparición en el horizonte neoyorquino fue Hoy, fundado el 16 de noviembre 1998 por la Times Mirror Corporation, que se fusionó posteriormente con la Tribune Publishing Company, su actual propietaria, editora -entre otras publicaciones- de los potentes Chicago Tribune y Los Angeles Times. Aunque el diario Hoy es el más joven de los rotativos hispano de Nueva York, éste ha ido creciendo con fuerza, pues en un sólo lustro llegó a una tirada de 60.000 ejemplares (37.000 en 1999 y 47.000 en 2000), muy por delante de los 32.000 de Noticias del Mundo y, tras pisarle los talones en el 2002 a El Diario - La Prensa. Posteriormente lo superó si hacemos caso a sus directivos, quienes en abril de 2003 nos dieron una cifra superior (unos 75.000); probablemente esa diferencia entre los datos del Hispanic Yearbook del 2002 y los de la empresa -que incluso meses después se vieron confirmados por ABC (Auditor Bureau Circulation) que les dio más 78.000- se deban a que ésta en su cuantificación incluía también la edición de este periódico para New Jersey, contabilizada como "área metropolitana" neoyorquina. Igualmente, desde septiembre de 2003, el periódico en español Éxito (editado por el Chicago Tribune) fue reemplazado por Hoy del mismo grupo, y en el verano de 2004 sacó su edición de Los Ángeles.

La evolución de los medios de comunicación en Nueva York en la década finisecular fue la que se refleja en la Tabla VI. Debemos comentar que la coincidencia de cifras en distintos años para el mismo medio no significa que se mantuvieron las mismas emisoras de radio o canales de televisión, pues -por una parte- en los últimos años se produjeron numerosas fusiones y -por otra-, por distintas circunstancias, unos medios pudieron haber cerrado para dejar paso a otros de nueva creación.

\footnotetext{
4 La empresa editora anunció que el 30 de abril del 2004 se publicaría el último número de Noticias de Mundo (como así fue) y que, por otra parte, concentraría parte de sus recursos -además de mantener los otros importantes medios que posee- en rediseñar y mejorar tecnológicamente el semanario Tiempos del Mundo, lo que beneficiaría su cobertura latinoamericana.
} 
Tabla VI. Los medios hispanos en Nueva York (1992-2002)

\begin{tabular}{|c|c|c|c|}
\hline Años & Publicaciones & Radio & Televisión \\
\hline 1992 & 6 & ------ & ----- \\
\hline 1995 & 19 & 11 & 10 \\
\hline 1999 & 25 & 10 & 7 \\
\hline 2002 & 29 & 10 & 7 \\
\hline
\end{tabular}

Fuente: Elaboración propia con datos de los Hispanic Yearbook.

Respecto a las publicaciones, ámbito específico de nuestro trabajo, se observa que es un sector que fue en claro ascenso, coincidente con el conjunto de prensa hispana en EE.UU., a diferencia de la prensa anglosajona que descendió a la cuarta parte en la misma década finisecular, como ratificaba The State of the News Media 2004. Según este informe, el número de diarios hispanos en EE.UU. creció de 14 en 1990 a 35 en 2002, triplicándose su difusión en ese mismo período (se pasó de un total -en números redondos- de 420.000 ejemplares a 1.700.000). Ese gran incremento se tradujo también en un volumen de ingresos por publicidad extraordinario, pasándose de los 111 millones de dólares recaudados por las publicaciones hispanas en 1990 a los 786 millones en 2002 (Hispanic Advertising Sales), lo que representó un alza del 31 por ciento comparado con el 2000. Todo ello son muestras fehacientes de la bonanza en crecimiento que experimenta tan sólo el sector de prensa hispana en EE.UU. precisamente en una época de recesión general y de caída continuada desde hace años, en especial desde el 2000, en cuanto a índices de difusión y de publicidad en la prensa.

De todos modos, publicaciones que aparecían en los primeros años de la década pasada (siguiendo los anuarios hispánicos), no aparecían en los últimos, y algunas aparecían en uno sólo de los años referidos. Dichos anuarios, además, no siempre contenían todos los datos que nos interesaban respecto al año de su fundación, el tipo de publicación, la periodicidad o la tirada. Asimismo, en esa documentación "no están todos los que son” (publicaciones menores), aunque "sí son todos los que están” (periódicos destacados). De hecho, en nuestra investigación, y con el fin de establecer comparaciones más matizadas al menos para el caso neoyorquino, estudiamos someramente juntamente con el análisis profundo los tres mencionados diarios 
algunas publicaciones semanales o quincenales, algunas de las cuales no aparecían en los anuarios pero que se distribuían desde el 2000 por las zonas hispanas de Nueva York. Por lo tanto, la Figura 1 que presentamos sirve sobre todo para proyectar grosso modo la evolución de las publicaciones neoyorquinas en español en la década finisecular.

Figura 1: Publicaciones hispanas en Nueva York

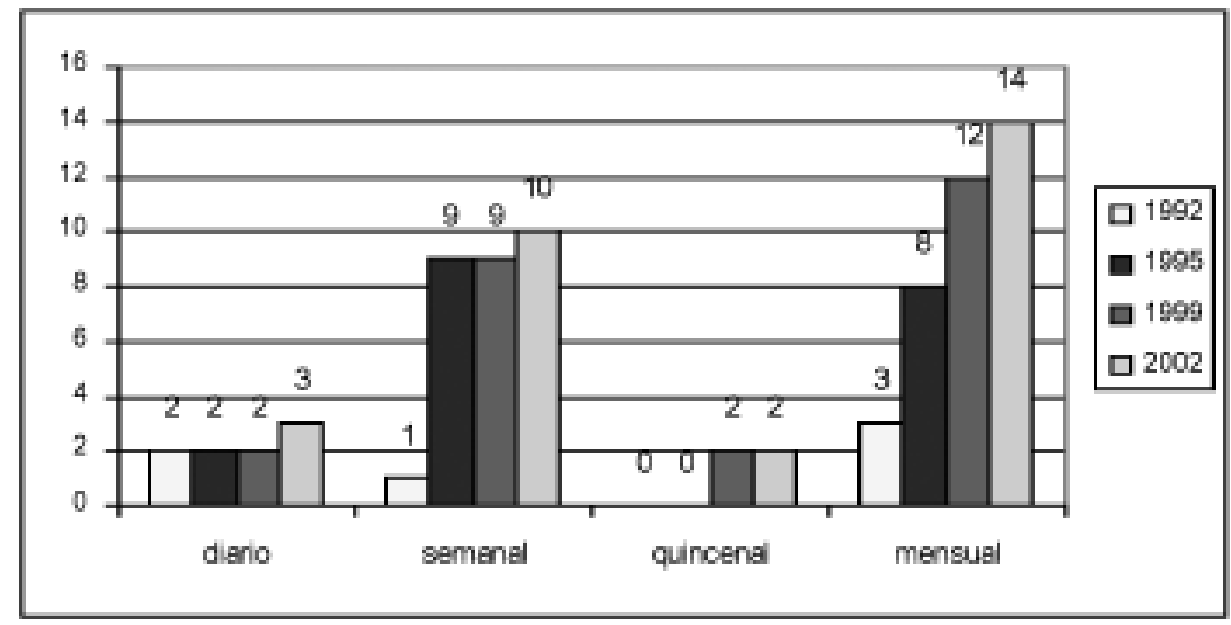

Fuente: Elaboración propia con datos del Hispanic Yearbook de 1992, 1995, 1999 y 2002.

\subsection{Estudio cualitativo-cuantitativo}

A continuación, y por razones de espacio, recogemos escuetamente lo substancial de las fichas analítico-descriptivas sólo de los tres diarios hispanos de Nueva York que efectuamos a raíz de nuestra investigación (El Diario - La Prensa, Hoy y Noticias del Mundo), así como solamente cuatro figuras (2, 3, 4 y 5) como resultado de un estudio pormenorizado de los contenidos informativos y publicitarios de los mismos para una semana de cada uno de los tres periódicos atendiendo a algunos de los aspectos de evidencias hispanas ${ }^{5}$.

5 De manera sintética, la metodología seguida en nuestro estudio fue la siguiente: El corpus central de nuestra investigación estuvo compuesto por varios ejemplares de los tres diarios en lengua española que se publicaban entonces en 
2.1.1. El Diario - La Prensa

\section{IDENTIDAD, REDACCIÓNY DIFUSIÓN}

Nombre: El Diario La Prensa (lo abreviamos como `DP’)

Lema: "El campeón de los hispanos"

Fundación: 1963, resultado de la fusión de La Prensa (1913) y El Diario de Nueva York (1948 como El Diario)

Propiedad: Latin Communications Group, del consorcio canadiense CPK Media.

Plantilla: Unos 50 redactores. El periódico cuenta con corresponsales propios en Puerto Rico y República Dominicana.

Fuentes: AP, AFP, EFE, y-ocasionalmente- otras.

Precio: 50 centavos \$.

Paginación: 48 páginas de formato $36 \mathrm{~cm}$. x $29 \mathrm{~cm}$.

la ciudad de Nueva York, en cantidad proporcional a la importancia de cada uno de ellos (en cuanto a tirada, antigüedad, proyección e influencia): 5 de El Diario - La prensa, 4 de Hoy y 3 de Noticias del Mundo, lo que en conjunto sumaron 556 páginas analizadas de mayo de 2000 (contrastadas posteriormente con otros ejemplares de 2003), las cuales dieron como resultado 604 fichas de noticias y 401 de anuncios (estableciéndose una operativa tipología de secciones y temas). La cuantificación de dicho análisis fue tan sólo de carácter indiciario para contrastar con el análisis cualitativo, tras una lectura profunda de los citados ejemplares, a su vez ponderada con entrevistas largas a una decena de periodistas hispanos, un intercambio de impresiones con cuatro estudiosos hispanos del tema, así como la consulta de diversos lectores y quiosqueros de los mismos periódicos. Ese análisis hemerográfico se completó con el estudio similar -aunque más sencillo y somero- de un ejemplar de otros siete periódicos hispanos -de periodicidad semanal o quincenal- como son El Especial, El Especialito, Impacto, Latino's, Noticiero Colombiano Hispano, Resumen y Tiempos del Mundo, y otro tanto con los tres diarios neoyorquinos en inglés de tipo popular o similar a los tres rotativos hispanos, Daily News, Newsday y New York Post, con el fin de establecer una comparación en cuanto al tipo y la calidad de periodismo. A todo ello, hay que añadir dos tipos de trabajo de campo; por un lado, las estancias -en horas de máxima faena- con observación participante en las redacciones de los tres diarios hispanos con el fin de conocer in situ sus modos de trabajo cotidiano; y, por otro, la visita a una docena de zonas hispanas de los cinco barrios neoyorquinos para comprobar en directo la vida pública de bastantes de esos ciudadanos en sus lugares de residencia, así como el intercambio de impresiones con algunos de ellos, en días laborables, de mercado y de fiesta. 
Edición electrónica: No tuvo hasta enero de 2003: www.eldiariony.com

Tirada: 72.000 ejemplares según el Hispanic Yearbook del 2002 y 52.558 según ABC (Auditor Bureau Circulation) para el primer trimestre de ese mismo año.

Lector destino: Sobre todo puertorriqueños, también muchos dominicanos, y cada vez más miembros de otras comunidades de origen centro y sudamericano, muchos de ellos recién inmigrados que no saben inglés.

\section{CONTENIDOS, COMPAGINACIÓN Y LENGUAJE}

Superficie de redacción: El porcentaje de la superficie dedicada a noticias en este diario es del $47,01 \%$, de las cuales el $28,23 \%$ son específicamente hispanas y el $18,78 \%$ no.

\section{Presentación}

- $\quad$ Las fotos son casi siempre de personajes, referidos a la noticia; abundan las de agencias.

- Inexistencia de fotoperiodismo, en el sentido de reportaje de fotos como relato de la información.

- Hay alguna fotonoticia.

- Compaginación sencilla, horizontal y sin romper columnas.

\section{Estructuras informativas:}

- $\quad$ En general, las noticias no siguen la estructura de "pirámide invertida".

- Las noticias de media página o menos no suelen incluir "ladillos".

- Las noticias de agencia suelen tener una estructura periodística correcta, en contraste con las noticias firmadas.

- $\quad$ Arranques muy personalizados, cargando el acento en el denominado "interés humano".

- $\quad$ Párrafos cortos, a menudo de una o dos frases, al estilo de las agencias. 


\section{Aspectos lingüísticos:}

- $\quad$ Escritura deficiente en las noticias de Redacción, incluso con incorrecciones.

- $\quad$ Los titulares de las noticias con frecuencia eliminan los artículos, a imitación de los titulares en lengua inglesa, pero por lo demás, suelen seguir estructuras castellanas.

- $\quad$ La tendencia es a utilizar un castellano neutro que no refleje las características particulares de ninguno de los países de origen.

- $\quad$ Hay expresiones claramente latinoamericanas: pedidos (en vez de peticiones), vocero (aunque también aparece portavoz), llamado (en vez de convocatoria), armar (como organizar), parqueo (como aparcamiento).

- $\quad$ Hay varios ejemplos de calcos semánticos, es decir, palabras tomadas del inglés que se adaptan a la fonética y ortografía castellana, pero que mantienen su significado original en inglés. También hay influencia del inglés en el uso de alguna construcción sintáctica.

- $\quad$ Aunque se utilizan indistintamente las palabras hispano y latino, predomina el uso de la primera. En muchos casos también se hace referencia a nacionalidades hispanas concretas: dominicano, mexicano, etc.

\section{PUBLICIDAD}

Superficie de publicidad: La superficie total dedicada a publicidad en este diario es de 38,54\%: un $24,98 \%$ corresponde a anuncios pagados, de los cuales un $17,32 \%$ son de carácter hispano, un $12,08 \%$ a anuncios clasificados y el restante 1,48\% es autopromoción.

\section{SIGNOS DE IDENTIDAD HISPANA}

- Junto a los nombres del equipo de dirección del diario, que aparece junto al logotipo del diario y la fecha de fundación, aparece en bilingüe una "Declaración de Misión: Informar, promover, impulsar y celebrar nuestra diversa comunidad latina”. 
- $\quad$ El periódico suele apoyar las fiestas y celebraciones de las comunidades hispanas.

- $\quad$ Noticias en secciones como "Comunidad" o "Nuestra gente" (donde se publican gratuitamente fotos de actos sociales de los lectores), pero también las de "Arte y cultura" o "Libros" son acerca de y para la comunidad hispana. En otra ocasión también se habla, por ejemplo, del aumento de estudiantes universitarios latinos.

- $\quad$ En varias ocasiones, las noticias se convierten en convocatorias para actividades de la comunidad; por ejemplo, la consagración de dirigentes religiosos o la celebración de una segunda vuelta de las elecciones peruanas.

\subsubsection{Hoy}

\section{IDENTIDAD, REDACCIÓNY DIFUSIÓN}

Nombre: Hoy (lo abreviamos como `hoy’)

Lema: "Llega al corazón de los hispanos", también "Para que conectes con tu gente”.

Fundación: 16 de noviembre de 1998.

Propiedad: Tribune Publishing Company.

Plantilla: Unos 20 redactores. A veces se nutre de informaciones elaboradas por las redacciones de los diversos periódicos en inglés del grupo.

Fuentes: AP, EFE (ambas alrededor del 15\%), Notimex, y-ocasionalmente- otras.

Precio: 25 centavos \$.

Paginación: 52 a 64 páginas de formato $35 \mathrm{~cm}$. x $27 \mathrm{~cm}$.

Edición electrónica: Desde el 2001: www.holahoy.com

Tirada: 60.000 según el Hispanic Yearbook del 2002 y 78.375 de media entre abril y septiembre de 2003 según ABC. 
Lector destino: Puertorriqueños (Bronx); dominicanos (Alto Manhattan); colombianos (Queens); mexicanos (Jackson Heights y otras áreas).

\section{CONTENIDOS, COMPAGINACIÓN Y LENGUAJE}

Superficie de redacción: El porcentaje de la superficie dedicada a noticias en este diario es del 56,09\%, de las cuales el 34,22\% son de carácter específicamente hispano y el 21,87 no.

\section{Presentación}

- $\quad$ Abundan las buenas fotos, aunque tampoco son espectaculares, ni se construyen relatos de la realidad a través de la fotografía, es decir, no hay fotoperiodismo.

- $\quad$ Sí que hay alguna fotonoticia, casi todas procedentes de agencia, sobre todo AP. También hay alguna foto procedente del diario hispano de Miami El Nuevo Herald.

- $\quad$ Pese a que la compaginación es horizontal y simple, se rompe alguna columna y suele ser adecuada. En la sección "Farándula" (Espectáculos) se permiten mayor creatividad.

\section{Estructuras informativas:}

- $\quad$ En las informaciones propias, los relatos pocas veces tienen una estructura periodística de "pirámide invertida"; sin embargo, las noticias que vienen redactadas desde las agencias sí están bien construidas.

- Prácticamente en ninguna información media o larga utilizan "ladillos”.

- $\quad$ Los arranques son de escaso impacto y sin cargar las tintas en los temas escabrosos, por ejemplo, los sucesos.

- $\quad$ Ligero predominio de párrafos medios sobre los cortos.

\section{Aspectos lingüísticos:}

- $\quad$ Escritura simple, pero relativamente correcta en las noticias firmadas. 
- Los titulares de las noticias, con frecuencia, eliminan palabras, sobre todo artículos y también algunos reflexivos, emulando el modelo lingüístico inglés.

- $\quad$ La tendencia es a utilizar un castellano neutro, es decir, sin giros lingüísticos de ninguno de los países de origen de los lectores, y si los hay, incluso se traducen entre paréntesis (yaniqueque [pastelillo]). Sin embargo, en algunas entrevistas se dejan las expresiones utilizadas por los entrevistados (chavos y chavas [chicos y chicas], en una entrevista a una joven cantante mexicana).

- $\quad$ Hay expresiones claramente latinoamericanas: carro, promociones, vocero (aunque también aparece portavoz), bienes raíces, mata de guineo, pararse (ponerse de pie).

- $\quad$ Hay numerosos ejemplos de calcos semánticos, pero que mantienen su significado original en inglés. También hay utilización de palabras en inglés directamente junto a otras castellanas.

- $\quad$ Se utilizan indistintamente las palabras hispano y latino tanto en noticias como en anuncios, aunque predomina la primera.

\section{PUBLICIDAD}

Superficie de publicidad: Este periódico dedica una media 35,42\% del espacio total del diario a publicidad: un $27,56 \%$ serían anuncios pagados, de los cuales un $16,53 \%$ tienen un carácter hispano; un 6,9\% serían anuncios clasificados y un 0,96\% estaría dedicado a autopromoción.

\section{SIGNOS DE IDENTIDAD HISPANA}

- $\quad$ En la sección "Punto de vista” (Opinión) hay varios ejemplos de posicionamiento y creación de opinión en los lectores sobre la comunidad hispana.

- $\quad$ A Puerto Rico se le da categoría de cualquier otro país hispano. 
- Aparece información sobre las elecciones en República Dominicana tanto en la sección de Local como en la de Internacional.

- El periódico parece interesado por la política tanto norteamericana, aunque enfocada hacia la comunidad hispana, como de los países latinoamericanos.

- $\quad$ El diario promociona y participa en fiestas latinas, bien con reseñas o con anuncios.

- Hay diversos anuncios o referencias a cadenas de televisión que emiten por sistema dual.

\subsubsection{Noticias del Mundo}

\section{IDENTIDAD, REDACCIÓNY DIFUSIÓN}

Nombre: Noticias del Mundo (lo abreviamos como `NM’)

Lema: No tiene.

Fundación: 22 abril 1980.

Propiedad: News World Communication, Inc.

Plantilla: Unos 12 redactores; se nutre también de la información de los corresponsales que trabajan para el semanario Tiempos del Mundo.

Fuentes: AP, EFE (predomina ligeramente sobre AP), y-ocasionalmente- otras.

Precio: 40 y 50 centavos \$ la edición diaria, y 50 y 60 centavos \$ la edición de fin de semana en Nueva York y Nueva Jersey o fuera de estas áreas, respectivamente.

Paginación: 28 páginas de formato $42 \mathrm{~cm}$. x $28 \mathrm{~cm}$.

Edición electrónica: No tiene.

Tirada: 32.000 ejemplares según el Hispanic Yearbook del 2002.

Lector destino: Sudamericanos de 35 a 45 años. 


\section{CONTENIDOS, COMPAGINACIÓN Y LENGUAJE}

Superficie de redacción: El porcentaje de la superficie dedicada a noticias en este diario es del 75,35\%, de las cuales el 51,27\% son hispanas y el 24,08\% no.

\section{Presentación:}

- $\quad$ La compaginación es horizontal, incluso cortando toda la página o la media página.

- $\quad$ No rompe columnas, a veces alguna foto las rompe.

- Diseño poco atractivo visualmente.

- $\quad$ Las fotos son de escaso interés: la mayoría de caras de personajes, proporcionadas por agencia y bastantes anónimas. También las hay realizadas por el mismo reportero-redactor, en deportes, por ejemplo.

\section{Estructuras informativas:}

- $\quad$ El estilo y la composición en general son algo descuidados.

- $\quad$ La titulación es preferentemente de carácter informativo, siempre sin subtítulos y sólo alguna vez con antetítulo.

- Teniendo en cuenta que es un periódico con pocas páginas, y que lleva poca publicidad, la información se elabora poco y con pocos redactores, aproximadamente un par de páginas por redactor. Buena parte de la información procede de agencias, incluso se llega a confeccionar alguna página entera o media con información de varias agencias, sin identificar y firmado como "Despachos combinados" o "Ecuador teme más sanciones por parte de la FIFA”, todas ellas de la sección de Deportes.

\section{Aspectos lingüísticos:}

- $\quad$ Escritura poco cuidada en la estructura periodística, salvo en las informaciones de agencia. Hay bastantes erratas tanto en los titulares como en las noticias.

- $\quad$ No parece existir nada parecido a lo que podría ser un libro de estilo para que lo sigan los redactores. 
- Los titulares de las noticias, con frecuencia eliminan palabras, sobre todo artículos y también algunos reflexivos, emulando el modelo lingüístico inglés.

- $\quad$ Hay numerosos ejemplos de palabras que se utilizan directamente en inglés, normalmente entre comillas

- $\quad$ La tendencia es a utilizar un castellano neutro que no refleje giros lingüísticos de ningún país concreto.

- Hay expresiones claramente latinoamericanas: carro, vocero (aunque también se utiliza portavoz, incluso dentro de la misma noticia), tener tanto años en un sitio o en un trabajo, balear (utilizada sobre todo en pasiva "fue baleado").

- $\quad$ Hay numerosos ejemplos de calcos semánticos, pero mantienen su significado original en inglés. También hay lo que podríamos llamar calcos sintácticos.

- También llama la atención que, a pesar de todos los errores y erratas que aparecen en los textos, en su sección de "Educación”, el diario dedique una subsección a ‘¿Conoce usted su idioma?', donde en un breve diálogo uno de los interlocutores da al otro una lección de gramática. Sin embargo, debemos decir que este mismo fragmento contiene errores y erratas.

- $\quad$ Respecto a la utilización de las palabras hispano y latino, se utilizan las dos indistintamente, aunque quizás predomine la primera.

\section{PUBLICIDAD}

Superficie de publicidad: Este periódico dedica muy poco espacio a publicidad, en conjunto, tan sólo un 11,89\%: un 7,57\% lo dedica a anuncios pagados, de los que un 4,83\% son de carácter hispano; un 3,75\% son anuncios clasificados y un 0,57\% es autopromoción. 


\section{SIGNOS DE IDENTIDAD HISPANA}

- $\quad$ Algunos artículos están dirigidos a crear conciencia de comunidad. Uno de los ejemplos más claros sería un artículo en el que Lydia Camarillo, la presidenta ejecutiva del Comité organizador de la Convención Demócrata, habla de la importancia del voto hispano en las elecciones en los Estados Unidos de 2000.

- $\quad$ Este diario patrocina algunas fiestas de comunidades hispanas, por ejemplo, "El cinco de mayo" y "La batalla de Puebla” mexicanas.

\section{Figura 2. Noticias hispanas en cada diario distribuidas por tema}

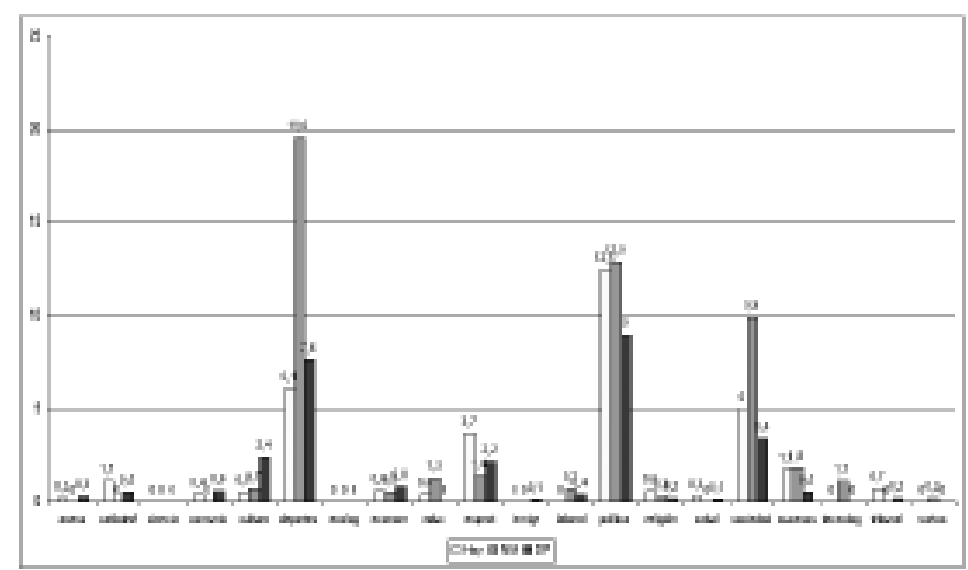

Fuente: Elaboración propia 
Diversidad latina y comunicación panhispana en la prensa en español de Nueva York

Figura 3. Anuncios hispanos por temas

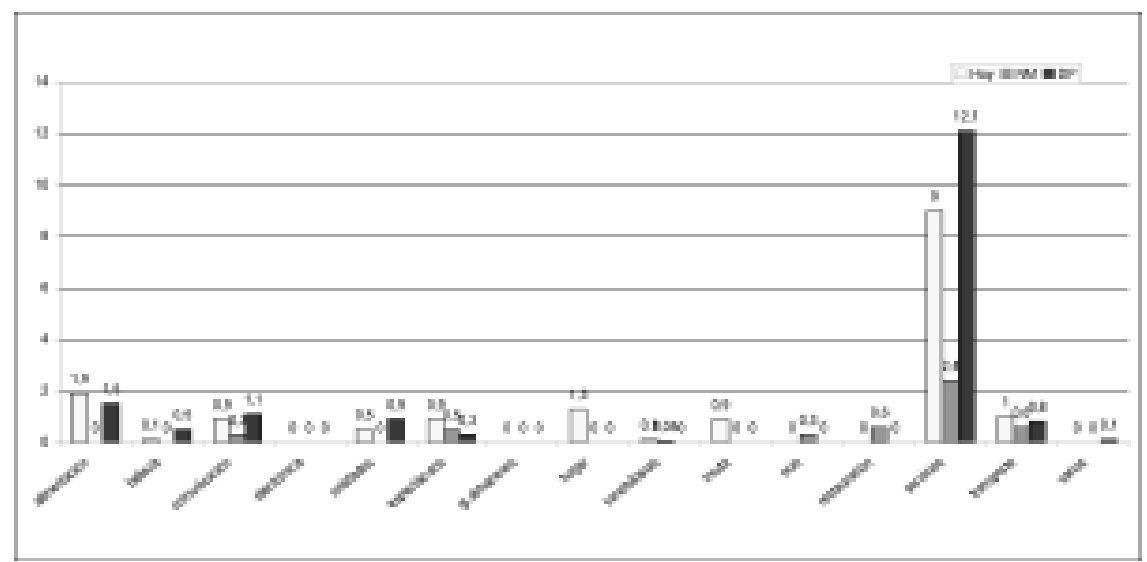

Fuente: Elaboración propia

Figura 4. Anuncios hispanos de servicios.

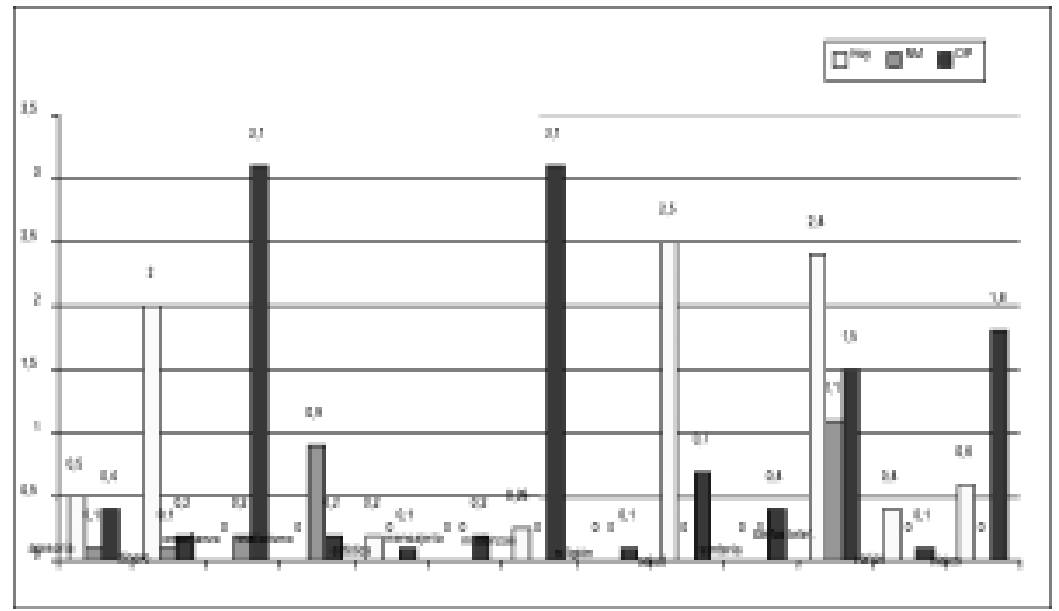

Fuente: Elaboración propia

$40 \mid n^{\circ} 6$ | doxa.comunicación 
Figura 5. Anuncios de servicios y asesoría

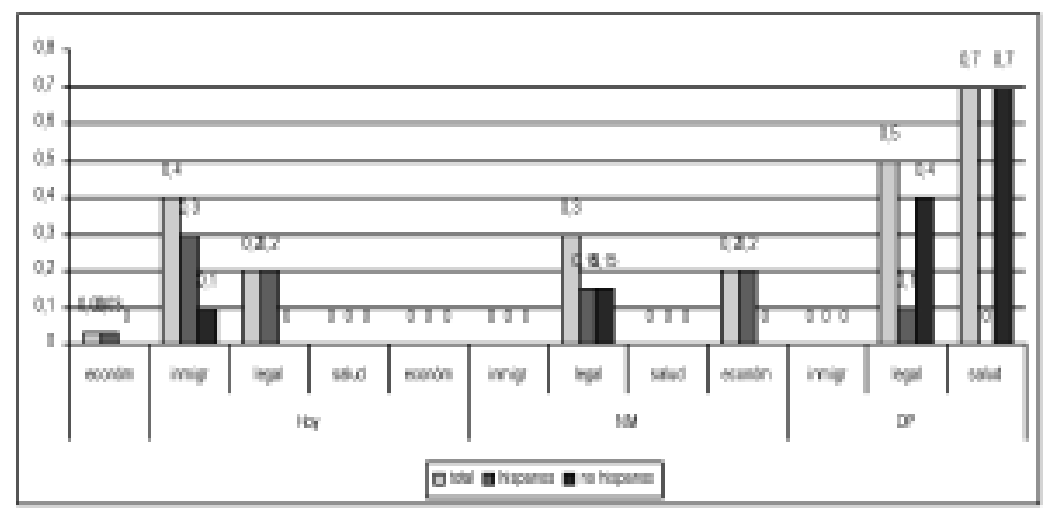

Fuente: Elaboración propia

\section{Conclusiones}

Estas son las principales conclusiones que extraemos de la información obtenida en nuestro trabajo de campo y de los resultados obtenidos en nuestro análisis hemerográfico (aquí simplemente recogido parcialmente):

El hecho de que en 2000 la cadena ABC de televisión empezara a emitir su principal informativo, World news tonight, doblado al español fue sin duda un síntoma claro de que los hispanos en Estado Unidos se habían convertido en la primera minoría y con un importante volumen de consumo. La evidencia que ratificó esa tendencia se produjo al principio del verano de 2003 cuando la boyante estación por cable New York 1 (NY1) -canal creado en 1992 por AOL Time Warner- amplió su oferta con un canal en español con el fin de conquistar los 3,7 millones de potenciales televidentes hispanos en esta ciudad. Justamente ambas estrategias televisivas eran la cara opuesta de los que había ocurrido unos años atrás con las tácticas de prensa. Así, por ejemplo, los Profiles en español de The New York Times, al inicio de los años 90 del siglo pasado, fracasaron y otro tanto acaeció cuando, dos años después, la edición traducida al español del Daily News de la misma ciudad apenas duró unos meses. 
¿Qué ha cambiado en apenas una década? Por supuesto, el crecimiento de los hispanos, que ha sido exponencial y cuya tendencia todo indica que proseguirá, es uno de los factores principales, pero no el único. La actitud de los hispanos de segunda o tercera generación hacia la lengua española también ha cambiado: "cifras oficiales apuntan que el $40 \%$ de la tercera generación continua utilizando el español como primera lengua" (Rojas Marco, 2003). Por un lado, porque ésta se ha prestigiado social y económicamente (ser competente en inglés y español ofrece mayores y mejores oportunidades $)^{6}$ y, por otro, porque aunque la presencia política de los hispanos todavía es muy insuficiente -como investiga, entre otros, Federico Subervi, pionero también de los estudios de medios hispanos en EE.UU. (Subervi, 1993; Subervi et altri, 1987) - su proyección sobre todo cultural (música, cine, deportes, comida, literatura.... $)^{7}$ los va consolidando como potencia emergente, cuyo reflejo mediático sólo se corresponde con los medios de comunicación hispanos, dado que los anglófilos los intentan absorber, ocultar o menospreciar. Según un estudio de la Universidad Vanderbilt (Nashville, Tennessee), los estereotipos de los informativos de las cadenas de televisión sobre los hispanos son exclusivamente negativos. Dos tercios de las noticias de la ABC, NBC, CBS y CNN relacionados con informaciones de hispanos en el 2002 trataban sobre crimen, terrorismo e inmigración ilegal ${ }^{8}$. Lógicamente, la imagen que difunden los medios hispanos sobre ellos

\footnotetext{
6 "La orientación de las empresas estadounidenses hacia los clientes hispanos -escribe Huntington (2004b: 29)- hace que necesiten cada vez más empleados bilingües, por lo que el bilingüismo influye en los salarios. En ciudades del suroeste como Phoenix y Las Vegas, los policías y bomberos bilingües cobran más que los que sólo hablan inglés. En Miami, según las conclusiones de un estudio realizado, las familias que sólo hablan español tienen unos ingresos medios de 18.000 dólares; las que sólo hablan inglés tienen ingresos medios de 32.000 dólares, y las familias bilingües ganan más de 50.000 dólares."

7 El ejemplo más paradigmático y sincrético sería la radio-fórmula neoyorquina La Mega, líder a menudo de audiencia desde 1999 y que, principalmente, emite música salsa [Otras emisoras hispanas de la ciudad que también radian música tropical y muy escuchadas por hispanos son Radio Única y Latino Mix]. Cabe recordar que ese tipo de música latina de influencia preferentemente caribeña -y que en los distintos países hispanoamericanos de donde surgió recibe según los ritmos o sones diversos nombres- empezó a denominarse así solamente en Nueva York, dado que su estilo tiene influencias del jazz y funky. Por tanto, en el caso que mencionamos se trata de un medio (comunicativo) y de un mensaje (musical) neoyorquinos genuinamente hispanos.

8 El estudio, publicado por la National Association of Hispanic Journalists (NAHJ), señalaba que, a pesar de que los hispanos representan el 13 por ciento de los habitantes de EE.UU., las noticias sobre ellos sólo representaban el 0,75\% de las que emitieron los 16.000 informativos en el 2002 por las grandes cadenas anglosajonas (ABC, NBC, CBS y CNN).
} 
mismos es no sólo más plural sino también más amable, por tanto, espejo y espejismo a la vez de la identidad panhispanica similar a la que construyen los medios norteamericanos en inglés sobre su identidad y cultura wasp (white anglosaxon protestant).

La necesidad de verse representados -los hispanos como tantos otros ciudadanos dentro o fuera de sus países de origen- y a la vez configurados con arreglo a unos patrones identitarios que les permitan mirarse y auto reflejarse con orgullo e incluso críticamente, pero por los suyos y desde lo propio, es lo que en tiempos de globalización está potenciando los medios nacionales o pannacionales de manera "glocal", dado que en la sociedad actual -como escribe Ulrich Beck (2003) - "lo transnacional y lo cosmopolita deberían entenderse como integración de la redefinición de lo nacional y lo local". Y eso, entre otras cosas es lo que está llevando a muchos "viejos" hispanos de EE.UU., y a los "nuevos", a prestar más atención y mayor dedicación a sus medios de comunicación frente a los anglos. Porque, como bien explica el cineasta marsellés Robert Guédiguian (2002), cuyas películas siempre se han circunscrito a Marsella, "cualquier comunidad humana necesita fabricar su imagen"9.

Para los "nuevos" hispanos de EE.UU. la demanda de medios en español todavía es más imprescindible porque, en tanto que inmigrados recientes -a menudo con poca formacióndemandan una información de servicios útiles a sus necesidades inmediatas, a la vez que desconocen o tienen dificultades con el inglés. Asimismo, es una muestra que el proceso de mundialización cultural de hegemonía "gringa" resulta para ellos más asfixiante al hallarse en el corazón del imperio, lo que les induce a buscar sus referentes culturales; en este sentido, la simple traducción de las noticias o de los deportes es insuficiente y por eso quieren -como nos decían todos los entrevistados y muchos hispanos con los que hablamos- un enfoque hispano, un tratamiento de la realidad informativa que les resulte familiar: es decir, que mire, escriba y hable en español. Llama la atención que, además de la progresión de los medios audiovisuales, gracias a la prensa y a internet en español entre los hispanos no sólo

\footnotetext{
9 Y sigue diciendo: "ver sus cuerpos, miradas, gestos que se asemejen a ellos en unas historias que se desarrollan en unos decorados que conocen. La imagen que los hombres ofrecen de sí mismos les constituye como tales, participa de su existencia como la lengua que hablan. Se trata de nuestra identidad, de la relación con nuestra historia individual y colectiva. En definitiva se trata de nuestro espejo".
} 
se ha producido un auge notable de la lectura en esta lengua, sino también de libros en español en EE.UU. -como síntoma de un aumento del consumo en general de productos culturales latinos- porque "para ellos [los hispanos] hablar y leer en español es una declaración de mundanidad", tal como explica Julio Ortega (2003) ${ }^{10}$, profesor de Estudios Hispánicos en EE.UU.

La prensa hispana de Nueva York también se ha transformado en los últimos años, impelida por la evolución de la misma comunidad latina en los distintos barrios. De entrada, ha habido cambios sustanciales entre los dos últimos censos (1990 y 2000). Aunque los puertorriqueños siguen siendo la nacionalidad con mayor número, han bajado 10 puntos, que se reparten entre otras nacionalidades como dominicanos, mexicanos, salvadoreños o peruanos. Téngase en cuenta que ahora hay una docena de hispanos de distintas nacionalidades que superan el uno por cien (unos 20.000) de los latinos que habitan Nueva York, lo que obliga a los medios de comunicación hispanos a tenerlos en cuenta y así se comprueba en diversos planos: variedad de redactores, anulación de modismos nacionalitarios, apertura a más países latinos, mayor atención a las diferencias y a su vez reforzamiento de lo común, lo hispano. Dos ejemplos: de los cinco miembros del consejo de redacción del 22 de mayo de 2000 (al que fuimos invitados a asistir) del "tradicionalmente puertorriqueño" El Diario - La Prensa, había cuatro nacionalidades latinoamericanas distintas, un pequeño reflejo de la docena que se encuentran entre su medio centenar de redactores; por otro lado, los tres presentadores del informativo en prime time de Univisión son cada uno de una nacionalidad hispana distinta; otros tanto ocurre con otras importantes cadenas hispanas de radio o televisión ${ }^{11}$. Por temas, enfoques, estilo, registro lingüístico, símbolos comunes, etc., el periodismo hispano

\footnotetext{
10 "En un país de 200 millones de habitantes -prosigue-, donde la mitad nunca leerá un libro después de la escuela, la población hispana, en descargo de su bajo promedio educativo, cultiva el valor del libro y, no sin candor, la figura del escritor como gloria cultural."

${ }^{11}$ Univisión -que cuenta con 53 estaciones de televisión, a las que se añaden las 29 de Telefutura y la mayor de cable, Galavisión, todas ellas del mismo grupo- creó el super gigante mediático hispano al fusionarse en septiembre de 2003 con el grupo de 68 emisoras de radio de Hispanic Broadcasting Corporation. Los otros importantes conglomerados radiotelevisivos hispanos, ambos con sede en Miami, son Telemundo -propiedad de General Electric, a través de la cadena NBC- que cuenta con 24 estaciones de televisión y Spanish Broadcasting System (SBS) con 24 emisoras de radio.
} 
está contribuyendo a conformar una especie de koiné identitaria, una suerte de superlingua forjada a partir de un determinado nivel de autoconciencia a la vez cultural e idiomática.

Como nos señalaba el editor metropolitano de Hoy, Javier Castaño, el periodismo hispano en EE.UU. refleja los vicios del periodismo latinoamericano (muy apegado a la política y así se constata en su alto porcentaje dedicado a este asunto, cuando la prensa semejante angloamericana, es decir la popular, apenas lo aborda; también es muy adjetivado) y apenas influido por el anglo. Sin embargo, el periodismo hispano en Estados Unidos se ocupa y preocupa de temas y cuestiones que necesitan los hispanos en este país (Figura 2), lo que le lleva a emplearse a fondo en un periodismo preferentemente de servicios (médicos, jurídicos, laborales, educativos, de vivienda, etc.) (Figuras 3, 4 y 5), por supuesto más allá de los deportes y el entretenimiento; dicho con otras palabras, es un periodismo que informa de la comunidad y para la comunidad, a la que mima y jamás cuestiona, como tampoco suele fiscalizar a los políticos mientras encajen en un patrón más o menos democrático. Tampoco critica a las empresas y grandes corporaciones, pero sí que suele ser muy activo en la defensa y denuncia de los problemas de las comunidades hispanas: discriminación, pobreza, precariedad educativa, embarazos no deseados, sida, droga, violencia... En este sentido, puede recordarnos el activismo periodístico de Pulitzer y su periódico para inmigrantes, de un siglo atrás, pero con la notable diferencia de que casi nunca investiga los temas como tampoco editorializa, no asumiendo por tanto, como aquél histórico World, la doble función de escuela y foro público o de maestro y tribuna. Por el contrario, el periodismo hispano sí parece recuperar o imitar de alguna manera aquella vieja función de "use-paper" que caracterizó a aquel emblemático rotativo neoyorquino de antaño, al ofrecer algunas pistas para sobrevivir y ser considerado en la gran urbe. Asimismo, el periodismo hispano en EE.UU. mantiene, como hiciera la mayoría de la black press norteamericana durante muchas décadas, un destacado papel en anunciar, mediante la agenda de actos, y en mostrar las actividades cívicas y sociales de la comunidad; de tal modo, que hace públicas noticias relativas a bodas, nacimientos, funerales, convocatorias o fiestas (a las que apoya y promociona), a través de ofrecer gratuitamente sus secciones de "Nuestra gente" (El Diario - La Prensa), "Comunidad" (Hoy) y "Sociales" (Noticias del Mundo). Y según comprobamos no lo hace sólo como elemento autorreferencial, para verse 
y recordarse, sino para potenciar entre la comunidad hispana un cierto sentimiento de orgullo, así como reforzar la identidad, con lemas como "informar, promover, impulsar y celebrar nuestra diversa comunidad latina" (El Diario - La Prensa) o "Llega al corazón de la los hispanos" o "Para que conectes con tu gente" (Hoy).

En cuanto a la calidad periodística de la prensa hispana en Nueva York, ésta es escasa en sus aspectos expresivos y de tratamiento de los temas, aunque no tanto en sus dispositivos de presentación, todo ello comprensible en relación con sus medios humanos y de equipamientos si los comparamos con los de los diarios -también populares- angloamericanos de esta ciudad (New York Post, Daily News y Newsday). Sin embargo, su corrección o no estilística, a la vez que sus planteamientos, son bastante similares entre los hispanos y los anglos, aunque en éstos sus redactores practican las técnicas más elaboradas de la estructura periodística como sean los "leads" y la "pirámide invertida" -aspectos éstos que en los hispanos casi sólo se aprecia en las informaciones procedentes de agencia-, o el fotoperiodismo como relato gráfico que, prácticamente, es inexistente. Tal vez, las únicas influencias del periodismo anglosajón, además de acentuar lo que en esta tradición se conoce como el "interés humano", sean las fórmulas de titulación, al omitir artículos y reflexivos, o los calcos semánticos o sintácticos del inglés.

La prensa hispana en Estados Unidos tiene una doble función relevante, aunque sea difícil valorar su grado y alcance Por un lado, en tanto que organizador social de esta comunidad pluriétnica de manera parecida a cómo lo hacían los periódicos en las primeras décadas del surgimiento de la sociedad de cultura y comunicación de masas. Y, por otro, como conformador -junto con otros medios y organizaciones (como, por ejemplo, la Federación Hispana, que agrupa a cuarenta asociaciones latinas) - de la identidad panhispana. Los nuevos hispanos en Estados Unidos pueden ser globales, en tanto que tales, sin dejar de ser locales, o sea, sin dejar de sentirse de la nacionalidad latinoamericana de origen, a la vez que pueden tener ciudadanía norteamericana, apreciando los valores y los beneficios de la sociedad de acogida (aún con los problemas propios de cualquier emigrante social), y, todo ello, sin tener que renunciar totalmente a su idiosincrasia ni tener que avergonzarse o esconderse de su país, lengua y cultura. Por su parte, los hispanos con más años de residencia en Estados Unidos, y 
todavía más sus hijos ya nacidos en este país, que en grados diversos mantienen ciertos rasgos de la identidad hispana o latina, han asimilado otra nacionalidad, al abrazar la ciudadanía norteamericana, y con ella un específico estatus jurídico que comporta derechos y deberes, así como un sentimiento de pertenencia y de identificación de símbolos, instituciones, mitos, etc. Sin embargo, la nueva prensa hispana, al menos en Nueva York, sin enfrentarse a los hispanos veteranos ni a lo que supone esa adscripción ciudadana, genera un cierto tipo de cultura política entre sus lectores ya que articula a la comunidad panhispánica sin convertirla en un gueto. Entre otras razones, porque es consciente que los hispanos en su conjunto e individualmente (algunos) tienen y tendrán cada vez más fuerza en términos culturales, económicos y políticos (como se ha demostrado en las elecciones primarias del 2008). Y, en consecuencia, el enfrentamiento social ni interesa a la comunidad ni a sus integrantes, ni por supuesto a las empresas editoras de esos periódicos ni a sus anunciantes, dado que todos, sujetos e instituciones sociales, están más o menos integrados al sistema norteamericano.

Y, finalmente, queremos señalar que los nuevos hispanos de Estados Unidos son eminentemente urbanos (a diferencia de antaño que eran campesinos en California o en los estados fronterizos con México), pues se han ido extendiendo sobre todo en las grandes ciudades y ocupándose en labores y profesiones típicamente urbanas. El caso de Nueva York, además, es paradigmático de los que podríamos denominar la "ciudad hispana transnacional", en el seno de las grandes metrópolis norteamericanas (Nueva York, Los Ángeles, Chicago, Houston, Philadelphia, Phoenix, San Diego, Dallas, San Antonio, San José, San Francisco, Austin, El Paso, etc.). Resulta elocuente porque los hispanos neoyorquinos -a diferencia de los de Los Ángeles o Miami- no viven en guetos, sino en barrios que además de la pluralidad latina, conviven con otras minorías étnicas, tales como los afroamericanos, los europeos nuevos, los asiáticos o los caribeños negros no latinos. Y los hispanos de Nueva York (cuyos porcentajes, salvo el Bronx que casi alcanza el 49\%, representan de un $20 \%$ a un 27\%, a excepción de Staten Island, sólo un $12 \%$ ) se mezclan con las citadas minorías que oscilan entre un 30\% y un 45\% . Así pues, los hispanos de Nueva York son, junto a esas otras minorías, una clase trabajadora multicultural. Y esa doble pluralidad "neonorteamericana" e hispana o latina supera el clásico barrio del inmigrante europeo o afroamericano en Estados Unidos, rompiendo el gueto 
(negro, judío, chino, italiano, centroeuropeo...). A esa importante transformación, hay que sumar cómo los hispanos -también de manera diferente de otras minorías tradicionales o nuevas- reinventan el espacio al recrearlo con su hábitos y estilos: colores, olores, estética, productos, música, mercados, etc. En definitiva, en los últimos años se ha ido produciendo un proceso de reconfiguración del hábitat urbano y de sus usos sociales, pasándose de un espacio / ambiente frío, comedido y gringo a otro cálido, exuberante y latino. Esas modificaciones se traducen en el binomio comunicación y ciudad de diversas maneras y adoptan formas y funciones, cuya expresión más evidente es la sustitución del restringido espacio público angloamericano por una socialidad latina o hispana, donde la plaza y el mercado, aunque sean improvisadas y no estables, se convierten en centros neurálgicos permanentes o esporádicos. Y como por un toque mágico, lugares lúgubres e inertes devienen espacios vivos de convivencia, o sea, de comunicación.

\section{Referencias bibliográficas}

- Beck, U. (2003): "La cuestión de la identidad", El País, 11 de noviembre de 2003.

- Davis, M. (2000): Magical Urbanism. Latinos Reinvent the U.S. Big City, Londres / Nueva York: Verso.

- Fox, G. (1997). Hispanic Nation. Culture, Politics and the Construction of Identity, Tucson: The University Press of Arizona.

- Fuentes, C. (2004): "El racista enmascarado", El País, 23 de marzo de 2004.

- García Canclini, N. (2003): "Un objeto de estudio que desafía a las disciplinas", Renglones, no 53, marzo-abril, pp. 6-16.

- Gibson, C. y Jung, K. (2002): "Historical Census Statistics on Population Totals by Race, 1790 to 1990, and by Hispanic Origin, 1970 to 1990, for the United States, Regions, Divisions, and States". Population Division, Working Paper, 56. U.S. Washington, D.C.: Census Bureau.

- Guédiguian, R. (2002): "Un desastre antropológico", El País, 31 de marzo de 2002. 
- Hispanic Advertising Sales (2002): Hispanic Advertising Sales in 2002, Carlsbad (CA): Latino Print Network, Kirk Whisler/WPR.

- Huntington, S. P. (2004a): Who Are We? America's Crisis of National Identity, Nueva York: Simon \& Schuster.

- Huntington, S. P. (2004b): "El reto hispano a EE.UU. ", edición española de Foreign Policy, abril-mayo 2004, pp. 20-35.

- Kanellos, N. (1994): "A Socio-Historic Study of Hispanic Newspapers in the United States", en Padilla, F. (ed.): Handbook of Hispanic cultures in the United States: Sociology. Houston (Tx) / Madrid: Arte Público Press / Instituto de Cooperación Iberoamericana, pp. 239-256.

- Krauze, E. (2004): "El falso profeta", El País, 13 de abril de 2004.

- Lacey, M. (2004): "El islam crece en Ruanda", El País, 8 de abril de 2004.

- Lomelí, F. (ed.) (1994): Handbook of Hispanic cultures in the United States: Literature and Art, Houston (Tx) / Madrid: Arte Público Press / Instituto de Cooperación Iberoamericana.

- Melville, M. (1994): “'Hispanic' Ethnicity, Race and Class”, en Weaver, T. (ed.): Handbook of Hispanic cultures in the United States: Anthropology. Houston (Tx) / Madrid: Arte Público Press / Instituto de Cooperación Iberoamericana, pp. 85-106.

- Ortega, J. (2003): "El libro en español en EE.UU.", El País, 3 de agosto de 2003.

- Padilla, F. (ed.) (1994). Handbook of Hispanic cultures in the United States: Sociology, Houston (Tx) / Madrid: Arte Público Press / Instituto de Cooperación Iberoamericana.

- Rojas Marcos, L. (2003) "Hispanos en EE.UU.: una convivencia en peligro", El País, 17 de febrero de 2003.

- State of the News Media 2004, The. (<http://www.stateofthenewsmedia.org/narrative_ethnicalternative_spanishpress.asp?media $=9>$ )

- Subervi, F. (1993). "Media”, en N. Kanellos (ed.), The Hispanic-American Almanac, capítulo 22. Detroit: Gale Research Inc. 621-674. (Reproducido posteriormente en Padilla, F. (ed), 
1994. 304-358).

- Subervi, F., Herrara, R. y Begay, M. (1987). “Toward an Understanding of the Role of the Mass Media in Latino Political Life”. Social Science Quarterly, 68:1, pp. 185-196.

- Torres Santiago, J. M. (1997). "El inicio del periodismo español", edición especial del 85 aniversario de El Diario - La Prensa, p. 15.

Portadas de los diarios analizados
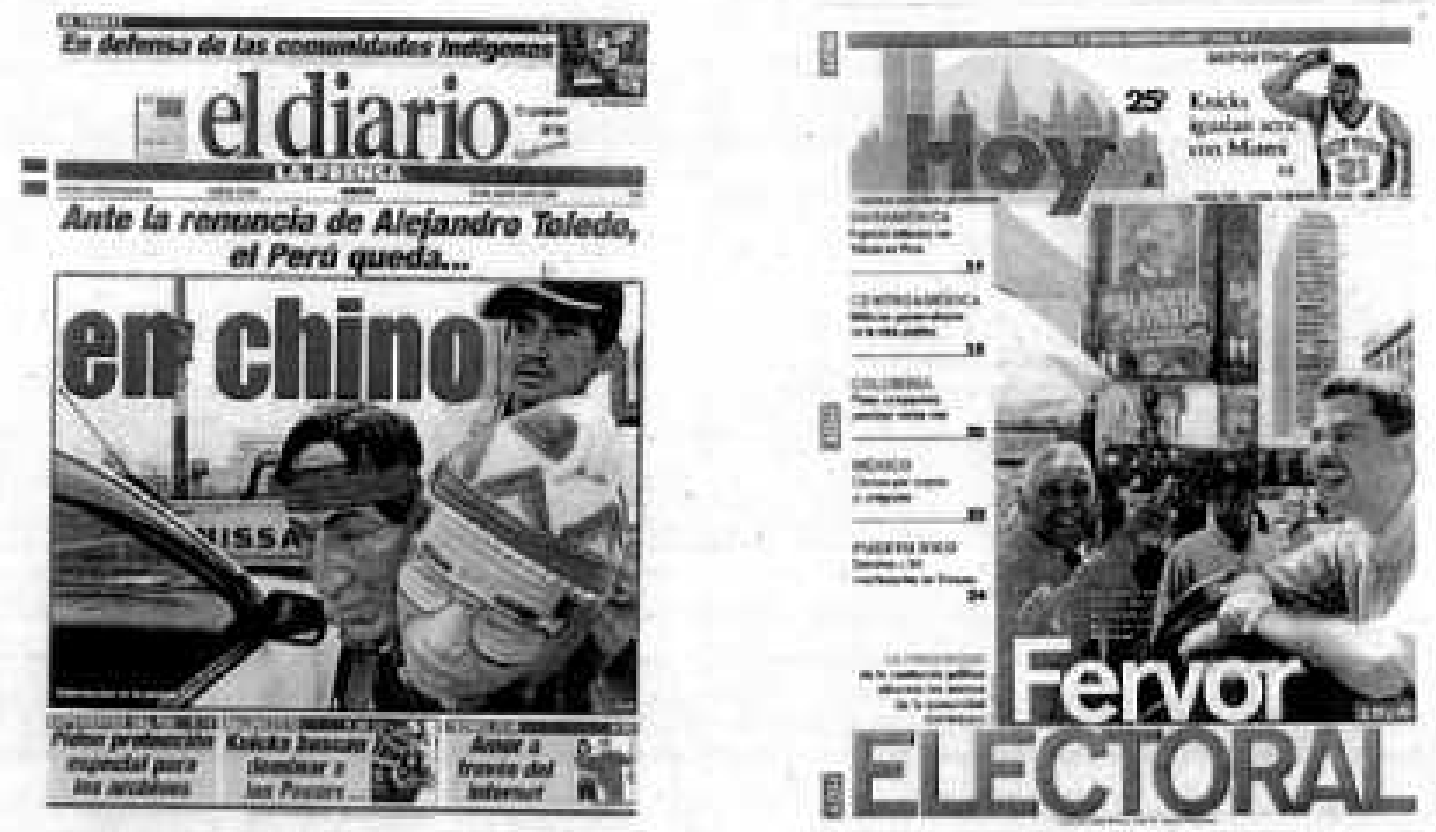

50 | n 6 | doxa.comunicación 


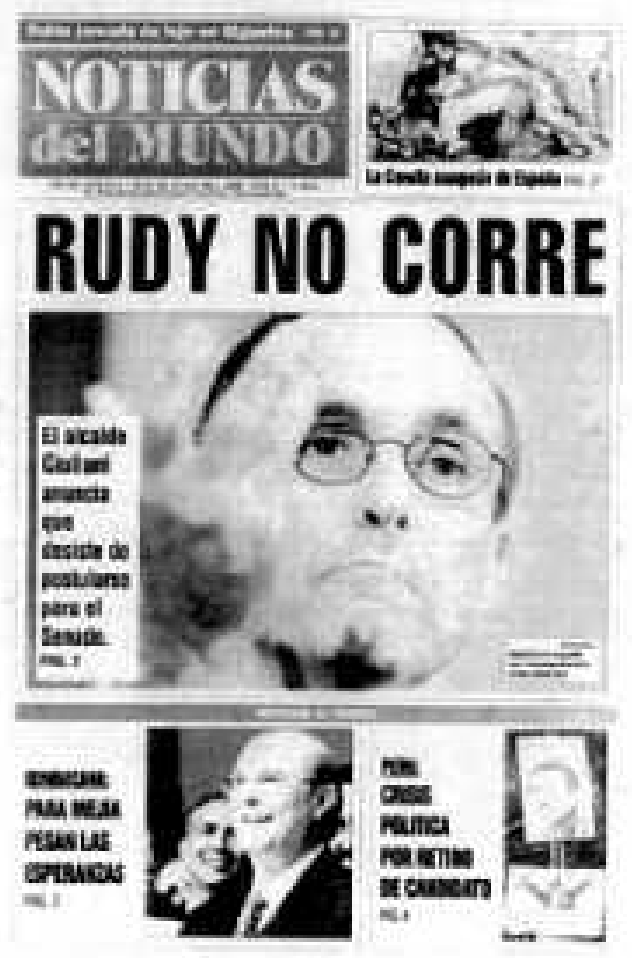


